\title{
Tool guide for lifestyle behavior change in a cardiovascular risk reduction program
}

This article was published in the following Dove Press journal:

Psychology Research and Behavior Management

16 August 2013

Number of times this article has been viewed

\author{
Nicole D White' \\ Thomas L Lenz' \\ Katherine Smith ${ }^{2}$ \\ 'Pharmacy Practice, Creighton \\ University School of Pharmacy and \\ Health Professions, Omaha, NE, \\ USA; ${ }^{2}$ PharmD Candidate Creighton \\ University School of Pharmacy and \\ Health Professions, Omaha, NE, USA
}

Correspondence: Nicole D White Creighton University School of Pharmacy and Health Professions, 2500 California

Plaza, Omaha, NE 68I78, USA

Tel + I 4022802797

Fax +l 4022802039

Email nicolewhite@creighton.edu

\begin{abstract}
Lifestyle medicine behaviors such as a healthy diet, physical activity, and tobacco avoidance, are the cornerstone of treatment in many chronic disease conditions, especially those related to the cardiovascular system. In fact, $80 \%$ of premature heart disease, stroke, and diabetes may be prevented through modification of these behaviors. The rate-limiting step in cardiovascular disease prevention is the implementation and maintenance of healthy lifestyle behaviors. The purpose of this paper is to provide and discuss a series of tools and strategies that can be used by health care providers to promote health behavior change in their practice.
\end{abstract}

Keywords: health behavior change, lifestyle medicine, cardiovascular disease

\section{Lifestyle behavior and cardiovascular risk}

In 2000, tobacco use, poor diet, physical inactivity, and alcohol consumption topped the list of actual causes of death in the United States. ${ }^{1}$ Research indicates that up to $80 \%$ of premature heart disease, stroke, and diabetes may be prevented through improvement of these modifiable risk factors. ${ }^{2}$ Not surprisingly, lifestyle modifications are addressed as first-line therapy in the treatment guidelines for many chronic disease conditions, especially those relating to the cardiovascular system. ${ }^{3-5}$

It is important to understand the "potency" or effectiveness of lifestyle behaviors in improving chronic disease indicators such as blood pressure, cholesterol, and glucose. Table 1 describes how physical activity, nutrition, tobacco cessation, alcohol moderation, stress reduction, and weight loss play a role in the management of hypertension, hyperlipidemia, and diabetes. ${ }^{3,4,6-11}$ Specific definitions regarding each of these lifestyle behaviors (eg, exercise frequency and Dietary Approach to Stop Hypertension) can be found on the website "Lifestyle is Medicine" at http://1m-rx.com. ${ }^{11}$ Of note, when combined, these behaviors have additive lowering effects on systolic blood pressure, low-density lipoprotein cholesterol, and estimated average glucose.

\section{Promotion of behavior change}

Changing behavior can be extremely challenging. In 1993, an article published in The Journal of the American Medical Association listed the most prominent contributors to mortality in the United States as tobacco use, diet and activity patterns, and alcohol. ${ }^{12}$ Almost a decade later, in 2000, researchers found the same four lifestyle behaviors again topped the list. ${ }^{1}$ This trend indicates that awareness of the risk associated with these behaviors alone is not enough motivation to change the behavior. 
Table I Lifestyle medicine in the treatment of chronic disease

\begin{tabular}{llll}
\hline Lifestyle behavior & $\begin{array}{l}\text { Reduction in systolic } \\
\text { blood pressure }\end{array}$ & $\begin{array}{l}\text { Reduction in estimated } \\
\text { average glucose }\end{array}$ & $\begin{array}{c}\text { Reduction in LDL } \\
\text { cholesterol (mg/dL) }\end{array}$ \\
\hline $\begin{array}{l}\text { Regular cardiovascular exercise } \\
\text { Regular resistance exercise }\end{array}$ & $4-9 \mathrm{mmHg}$ & $\begin{array}{l}19 \mathrm{mg} / \mathrm{dL} \\
18 \mathrm{mg} / \mathrm{dL}\end{array}$ \\
$\begin{array}{l}\text { Adopting DASH eating plan } \\
\text { Limited salt intake }\end{array}$ & $8-14 \mathrm{mmHg}$ & $\mathrm{Up} \mathrm{to} 100 \mathrm{mg} / \mathrm{dL}$ & \\
$\begin{array}{l}\text { Limited carbohydrate (starch/sugar) intake } \\
\text { Increased soluble fiber intake }\end{array}$ & $2-8 \mathrm{mmHg}$ & $3 \%-5 \%$ \\
$\begin{array}{l}\text { Increased plant stanol/sterol intake } \\
\text { Decreased saturated fat and dietary } \\
\text { cholesterol intake }\end{array}$ & & $5 \%-15 \%$ \\
Smoking cessation & & & $11 \%-15 \%$ \\
Limited alcohol intake & & & $1.7 \%$ \\
Stress reduction & $3.5 \mathrm{mmHg}$ & & \\
Weight loss & $2-4 \mathrm{mmHg}$ & $20 \mathrm{mg} / \mathrm{dL}$ & $5 \%-8 \%$ \\
\hline
\end{tabular}

Notes: Data from the website "Lifestyle is Medicine". Available at: http://lm-rx.com/."

Abbreviations: DASH, Dietary Approach to Stop Hypertension; LDL, low-density lipoprotein.

Many theories of behavior change exist. Among the most common related to health behavior change are the transtheoretical model of behavior change, the health belief model, and social cognitive theory. The purpose of this paper is to describe several of the most common theories of health behavior change and provide a series of tools that can be used to apply the theories in clinical practice.

\section{Transtheoretical model of behavior change}

The transtheoretical model of behavior change was first used to describe tobacco use and cessation behavior. ${ }^{13}$ The model describes the continuum of stages in behavior change. The first stage is precontemplation, where the change is not being considered or the subject has no interest in changing the behavior. The precontemplation stage precedes the contemplation stage, where the change is considered. Preparation is the stage in which options for change are examined. Preparation is followed by the action stage where the new behavior is initiated. Action proceeds to either "maintenance" of the behavior or "relapse" to the old behavior. With each stage of change, a different intervention on the part of the health care provider is appropriate. During the precontemplation and contemplation stage, the health care provider should reinforce the importance of the behavior and provide education on the benefits of changing the behavior. During the preparation stage, assistance and resources should be provided to aid in successful modification. During the action and maintenance stages, positive reinforcement of the behavior should occur. Should the patient enter the relapse stage, barriers to behavior change should be identified and addressed. Several clinical tools exist that incorporate the transtheoretical model, including the 5 As method (ask, advise, assess, assign, arrange) and the Readiness Ruler. ${ }^{14,15}$ A third tool, the "Readiness" and "Confidence to Change" survey, incorporates concepts from the transtheoretical model and is described below.

\section{Health belief model}

According to the health belief model, an individual will change a behavior if they perceive a personal threat or illness secondary to the behavior and believe changing the behavior will effectively avert this threat or illness. ${ }^{16}$ For example, if an individual experiences hyperglycemia with cessation of exercise and has a family history of dialysis and kidney transplant secondary to uncontrolled diabetes, the individual may have increased motivation to restart their exercise routine. The threat in this example is hyperglycemia and the possibility of kidney failure. The behavior is exercise, which the individual believes from personal experience has an effect on blood sugar control. Taken together, the threat and the knowledge of benefit from exercise may increase motivation on the part of the individual to change the behavior. The "Risk Assessment Calculator", described below, incorporates concepts from the health belief model and can be used in a clinical setting to promote behavior change by the patient.

\section{Social cognitive theory}

Social cognitive theory, specifically social learning theory, suggests that motivation to change behavior is increased when the subject believes the behavior is important and has confidence that they can successfully change the behavior. ${ }^{17}$ When applied to the aforementioned example, the individual with hyperglycemia is aware that both increased physical activity and reduction in carbohydrate consumption can lower blood sugar and reduce 
her risk for kidney disease. Because she has exercised regularly in the past, she is confident that she can make this change again, but is less confident about reducing her carbohydrate intake. Because of the difference in her Confidence to Change the two behaviors, the social cognitive theory suggests that she will be most successful when initiating exercise because she believes she can modify this behavior. This theory is important to consider when developing a lifestyle medicine plan and setting patient-specific goals to modify behavior. The "Readiness" and "Confidence to Change behavior" questionnaires and the "Personalized lifestyle medicine" program incorporate this theory and are described in detail below.

\section{Motivational interviewing}

Another important behavior change concept lies in the technique used to deliver appropriate behavior change interventions. Motivational interviewing is a form of patient counseling that has been found to be effective in reducing maladaptive behaviors and promoting positive health behavior changes. ${ }^{17}$ The approach focuses on eliciting a person's intrinsic motivation to change, rather than advice-giving or confrontation from a health professional authority. Key to this counseling technique is displaying empathy, rolling with patient resistance, and supporting self-efficacy. ${ }^{18}$ Displaying empathy can be done through reflective listening and by vocally acknowledging the difficulty in behavior change. Rolling with resistance involves the absence of confrontation and in its place a discussion of new perspectives or alternative solutions for barriers to change. Finally, supporting self-efficacy can be done through assuring the patient that you believe in their ability to make the change. Motivational interviewing is a skill set that develops with knowledge and practice, and is extremely advantageous in effectively using the clinical tools described below.

\section{Behavior change tools}

Health care providers need tools to assist patients in making healthy lifestyle choices. Described below are examples of tools developed to apply behavior change theories practically in the clinic setting.

\section{Risk assessment worksheet}

The risk assessment worksheet was adapted from the Framingham 10-year General Cardiovascular Disease Risk Calculator. ${ }^{19}$ This tool can be used interactively with the patient to communicate personal cardiovascular risk and facilitate a discussion as to how lifestyle modifications can reduce that risk. The risk calculations are sex-specific and thus, two separate tools were developed. Figure 1 depicts the women's risk assessment worksheet and Figure 2 depicts the men's risk assessment worksheet.

The worksheet, when used interactively, allows the patient to watch as their individual risk factors are scored to determine an overall cardiovascular risk score. The health care provider should step through each risk factor category and identify the associated risk score based on the patient's age, health history, and laboratory values. The baseline score for each risk factor should be written under the column "Current risk score". This process illustrates for the patient which risk factors are particularly problematic (those that carry the highest point value). The sum of the individual risk factor scores should be calculated and used to determine the patient's overall cardiovascular risk. This cardiovascular risk estimate is communicated as a percentage chance of coronary death, myocardial infarction, coronary insufficiency, angina, ischemic stroke, hemorrhagic stroke, transient ischemic attack, peripheral arterial disease, or heart failure in the next ten years. The sum of risk scores can also be used to determine a heart or vascular age. The heart/vascular age provides an easily understood analogy of risk based on decreased life expectancy. The heart/vascular age can be a powerful education tool, especially for those patients with low health literacy. ${ }^{20}$

Following calculation of baseline cardiovascular risk and heart/vascular age, the health care provider should again step though each risk factory category, this time identifying optimal risk scores that could be accomplished through adopted and sustained lifestyle medicine behaviors. The optimal score for each risk factor category should be written under the column "Optimal risk score" and the lifestyle behaviors necessary to achieve the optimal risk score should be described under the column "Lifestyle medicine recommendations." This process allows the health care provider to start an open discussion about lifestyle behaviors and their benefits in chronic disease prevention and treatment as they relate directly to the patient being assessed.

Table 2 shows an example of risk calculation using both baseline and optimal risk factor scores in a 54-year-old woman. As shown, age is a nonmodifiable risk factor and the risk scores are thus equal currently and optimally. Total cholesterol is already optimized according to treatment guidelines and no behavior change is recommended at this time. ${ }^{4}$ High-density lipoprotein cholesterol could be improved by initiation of an exercise program. A high-density lipoprotein cholesterol increase of only $2 \mathrm{mg} / \mathrm{dL}$ would reduce the patient's risk score by one point. Systolic blood pressure is one of two major problem areas for this patient. After speak- 


\begin{tabular}{|c|c|c|c|c|c|}
\hline \multicolumn{6}{|c|}{ Women's risk assessment worksheet } \\
\hline \multicolumn{2}{|r|}{ Points } & Risk factor & Current risk score & Optimal risk score & $\begin{array}{l}\text { Lifestyle modification } \\
\text { recommendations }\end{array}$ \\
\hline & & Age & & & \\
\hline & 0 & $30-34$ & & & \\
\hline & 2 & $35-39$ & & & \\
\hline & 4 & $40-44$ & & & \\
\hline & 5 & $45-49$ & & & \\
\hline & 7 & $50-54$ & & & \\
\hline & 8 & $55-59$ & & & \\
\hline & 9 & $60-64$ & & & \\
\hline & 10 & $65-69$ & & & \\
\hline & $\mathrm{II}$ & $70-74$ & & & \\
\hline \multirow{2}{*}{\multicolumn{2}{|c|}{12}} & $75+$ & & & \\
\hline & & HDL & & & \\
\hline & -2 & $60+$ & & & \\
\hline & -1 & $50-59$ & & & \\
\hline & 0 & $45-49$ & & & \\
\hline & $\mathrm{I}$ & $35-44$ & & & \\
\hline \multirow{2}{*}{\multicolumn{2}{|c|}{2}} & $<35$ & & & \\
\hline & & Total cholesterol & & & \\
\hline \multicolumn{2}{|r|}{0} & $<160$ & & & \\
\hline \multicolumn{2}{|r|}{ I } & $160-199$ & & & \\
\hline \multicolumn{2}{|r|}{3} & $200-239$ & & & \\
\hline \multicolumn{2}{|r|}{4} & $240-279$ & & & \\
\hline \multicolumn{2}{|r|}{5} & $280+$ & & & \\
\hline Treated & Untreated & Systolic blood pressure & & & \\
\hline-1 & -3 & $<120$ & & & \\
\hline 2 & 0 & $120-129$ & & & \\
\hline 3 & $\mathrm{I}$ & $130-139$ & & & \\
\hline 5 & 2 & $140-149$ & & & \\
\hline 6 & 4 & $150-159$ & & & \\
\hline \multirow{2}{*}{\multicolumn{2}{|c|}{7}} & $160+$ & & & \\
\hline & & Diagnosed diabetes & & & \\
\hline \multicolumn{2}{|r|}{0} & No & & & \\
\hline \multirow{2}{*}{\multicolumn{2}{|c|}{4}} & Yes & & & \\
\hline & & Tobacco use & & & \\
\hline & 0 & No & & & \\
\hline & 3 & Yes & & & \\
\hline \multicolumn{3}{|c|}{ Total score } & & & \\
\hline & & Point total & & & \\
\hline & & 10 year CVD risk & & & \\
\hline & & Heart age & & & \\
\hline
\end{tabular}

\begin{tabular}{|c|c|c|c|c|c|c|c|c|}
\hline Point total & $\begin{array}{l}10 \text { year CVD } \\
\text { risk }\end{array}$ & Heart age & Point total & $\begin{array}{l}10 \text { year CVD } \\
\text { risk }\end{array}$ & Heart age & Point total & $\begin{array}{l}10 \text { year CVD } \\
\text { risk }\end{array}$ & $\begin{array}{l}\text { Heart } \\
\text { age }\end{array}$ \\
\hline$<-1$ & $<1 \%$ & $<30$ & 6 & $3.3 \%$ & 45 & 14 & $11.7 \%$ & 79 \\
\hline-1 & $1 \%$ & $<30$ & 7 & $3.9 \%$ & 48 & 15 & $13.7 \%$ & $>80$ \\
\hline 0 & $1.2 \%$ & $<30$ & 8 & $4.5 \%$ & 51 & 16 & $15.9 \%$ & $>80$ \\
\hline 1 & $1.5 \%$ & 31 & 9 & $5.3 \%$ & 55 & 17 & $18.5 \%$ & $>80$ \\
\hline 2 & $1.7 \%$ & 34 & 10 & $6.3 \%$ & 59 & 18 & $21.5 \%$ & $>80$ \\
\hline 3 & $2 \%$ & 36 & 11 & $7.3 \%$ & 64 & 19 & $24.8 \%$ & $>80$ \\
\hline 4 & $2.4 \%$ & 39 & 12 & $8.6 \%$ & 68 & 20 & $28.5 \%$ & $>80$ \\
\hline 5 & $2.8 \%$ & 42 & 13 & $10 \%$ & 73 & $21+$ & $>30 \%$ & $>80$ \\
\hline
\end{tabular}

Figure I Women's risk assessment worksheet.

Abbreviations: HDL, high-density lipoprotein cholesterol; CVD, cardiovascular disease. 


\begin{tabular}{|c|c|c|c|c|c|}
\hline \multicolumn{6}{|c|}{ Men's risk assessment worksheet } \\
\hline \multicolumn{2}{|r|}{ Points } & Risk factor & Current risk score & Optimal risk score & $\begin{array}{l}\text { Lifestyle modification } \\
\text { recommendations }\end{array}$ \\
\hline & & Age & & & \\
\hline \multicolumn{2}{|r|}{0} & $30-34$ & & & \\
\hline \multicolumn{2}{|r|}{2} & $35-39$ & & & \\
\hline \multicolumn{2}{|r|}{5} & $40-44$ & & & \\
\hline \multicolumn{2}{|r|}{6} & $45-49$ & & & \\
\hline \multicolumn{2}{|r|}{8} & $50-54$ & & & \\
\hline \multicolumn{2}{|r|}{10} & $55-59$ & & & \\
\hline \multicolumn{2}{|r|}{11} & $60-64$ & & & \\
\hline \multicolumn{2}{|r|}{12} & $65-69$ & & & \\
\hline \multicolumn{2}{|r|}{14} & $70-74$ & & & \\
\hline \multirow{2}{*}{\multicolumn{2}{|c|}{15}} & $75+$ & & & \\
\hline & & HDL & & & \\
\hline \multicolumn{2}{|r|}{-2} & $60+$ & & & \\
\hline \multicolumn{2}{|r|}{-1} & $50-59$ & & & \\
\hline \multicolumn{2}{|r|}{0} & $45-49$ & & & \\
\hline \multicolumn{2}{|r|}{ I } & $35-44$ & & & \\
\hline \multirow{2}{*}{\multicolumn{2}{|c|}{2}} & $<35$ & & & \\
\hline & & Total cholesterol & & & \\
\hline \multicolumn{2}{|r|}{0} & $<160$ & & & \\
\hline \multicolumn{2}{|r|}{ I } & $160-199$ & & & \\
\hline \multicolumn{2}{|r|}{2} & $200-239$ & & & \\
\hline \multicolumn{2}{|r|}{3} & $240-279$ & & & \\
\hline \multicolumn{2}{|r|}{4} & $280+$ & & & \\
\hline Treated & Untreated & Systolic blood pressure & & & \\
\hline 0 & -2 & $<120$ & & & \\
\hline 2 & 0 & $120-129$ & & & \\
\hline 3 & $\mathrm{I}$ & $130-139$ & & & \\
\hline 4 & 2 & $140-159$ & & & \\
\hline \multirow{2}{*}{\multicolumn{2}{|c|}{5}} & $160+$ & & & \\
\hline & & Diagnosed diabetes & & & \\
\hline & 0 & No & & & \\
\hline \multicolumn{2}{|r|}{3} & Yes & & & \\
\hline & & Tobacco use & & & \\
\hline & 0 & No & & & \\
\hline & 4 & Yes & & & \\
\hline \multicolumn{3}{|c|}{ Total score } & & & \\
\hline & & Point total & & & \\
\hline & & 10 year CVD risk & & & \\
\hline & & Heart age & & & \\
\hline
\end{tabular}

\begin{tabular}{|c|c|c|c|c|c|c|c|c|}
\hline Point total & $\begin{array}{l}10 \text { year CVD } \\
\text { risk }\end{array}$ & Heart age & Point total & $\begin{array}{l}10 \text { year CVD } \\
\text { risk }\end{array}$ & Heart age & Point total & $\begin{array}{l}10 \text { year CVD } \\
\text { risk }\end{array}$ & $\begin{array}{l}\text { Heart } \\
\text { age }\end{array}$ \\
\hline$<-2$ & $<1 \%$ & $<30$ & 5 & $3.9 \%$ & 40 & 13 & $15.6 \%$ & 64 \\
\hline-2 & $1.1 \%$ & $<30$ & 6 & $4.7 \%$ & 42 & 14 & $18.4 \%$ & 68 \\
\hline-1 & $1.4 \%$ & $<30$ & 7 & $5.6 \%$ & 45 & 15 & $21.6 \%$ & 72 \\
\hline 0 & $1.6 \%$ & 30 & 8 & $6.7 \%$ & 48 & 16 & $25.3 \%$ & 76 \\
\hline I & $1.9 \%$ & 32 & 9 & $7.9 \%$ & 51 & 17 & $29.4 \%$ & $>80$ \\
\hline 2 & $2.3 \%$ & 34 & 10 & $9.4 \%$ & 54 & $18+$ & $>30 \%$ & $>80$ \\
\hline 3 & $2.8 \%$ & 36 & 11 & $11.2 \%$ & 57 & & & \\
\hline 4 & $3.3 \%$ & 38 & 12 & $13.2 \%$ & 60 & & & \\
\hline
\end{tabular}

Figure 2 Men's risk assessment worksheet.

Abbreviations: HDL, high-density lipoprotein cholesterol; CVD, cardiovascular disease. 
Table 2 Women's risk assessment example

\begin{tabular}{|c|c|c|c|c|}
\hline Risk factor & Patient data & Current risk score & Optimal risk score & Lifestyle recommendations \\
\hline Age, years & 54 & 7 & 7 & N/A \\
\hline Total cholesterol & $189 \mathrm{mg} / \mathrm{dL}$ & I & 1 & $\begin{array}{l}\text { Cholesterol is well controlled, no } \\
\text { additional lifestyle modifications } \\
\text { necessary at this time }\end{array}$ \\
\hline HDL cholesterol & $43 \mathrm{mg} / \mathrm{dL}$ & I & 0 & $\begin{array}{l}\text { Increased physical activity for an } \\
\mathrm{HDL} \text { goal of } 45 \mathrm{mg} / \mathrm{dL}\end{array}$ \\
\hline Systolic blood pressure & 145 mmHg (treated) & 5 & 2 & $\begin{array}{l}\text { Medication adherence, smoking } \\
\text { cessation and improved nutrition } \\
\text { for a SBP goal of } 129 \mathrm{mmHg}\end{array}$ \\
\hline Smoking status & Smoker & 3 & 0 & Smoking cessation \\
\hline \multirow[t]{2}{*}{ Diagnosis of diabetes? } & No & 0 & 0 & $\mathrm{~N} / \mathrm{A}$ \\
\hline & Total & 17 & 10 & \\
\hline Cardiovascular disease risk & & $18.5 \%$ & $6.3 \%$ & \\
\hline Heart/vascular age & & $>80$ & 59 & \\
\hline
\end{tabular}

Abbreviations: HDL, high-density lipoprotein; SBP, systolic blood pressure.

ing with the patient, you determine she is not adherent with her antihypertensive medication and has a poor fruit and vegetable intake. Through medication adherence and behavior changes, such as smoking cessation and improved nutrition, the patient could decrease her systolic blood pressure by $16 \mathrm{mmHg}$, and in doing so, reduce her risk score by three points. The second major problem area for this patient is her tobacco use, which adds three points to her total risk score. Through cessation of tobacco, she could eliminate those points and improve her blood pressure. Through lifestyle (initiating exercise, medication adherence, improved nutrition, and tobacco cessation), this patient could reduce her risk score from 17 to 10 points which reduces her 10-year cardiovascular risk from $18.5 \%$ to $6.3 \%$ and her heart age from $>80$ to 59 years of age.

The risk assessment worksheet was modeled from health belief model concepts. The calculation of risk percentage and heart/vascular age demonstrates a direct health threat to the patient, namely, a cardiovascular disease event. Calculating the optimal risk score and showing the patient how lifestyle can help to achieve optimal scores reinforces the concept that changing the behavior will successfully avert the risk of heart disease. This tool provides excellent risk assessment education and when used as a part of a cardiovascular risk reduction program can be used successfully to motivate behavior change. ${ }^{21}$

\section{Readiness and Confidence to Change surveys}

As discussed previously, several clinical tools are available that apply the concepts of the transtheoretical model of behavior change in a practical way. The Readiness and Confidence to Change surveys incorporate both the transtheoretical model and social cognitive theory to enhance the quality of information derived from using the tool.

The Readiness survey assesses the patient's stage of behavior change while the Confidence to Change survey assesses the patient's level of self-efficacy to adopt or sustain the behavior. The surveys can be tailored to assess any set of behaviors desired. For example, in an endocrinology clinic, annual influenza vaccinations, foot and eye examinations, regular self-monitoring of blood glucose, medication adherence, and carbohydrate counting may be the key behaviors in the management of diabetes included in the survey, while salt restriction, increased fruit and vegetable intake, reduced stress, smoking cessation, and regular exercise are the behaviors assessed in an hypertension clinic.

With each behavior, the patient is asked to determine how "ready" they are to incorporate the behavior into their lifestyle using the following scale: 22

(5) No interest in this lifestyle behavior at this time;

(4) Thinking about implementing this lifestyle behavior sometime in the next few months;

(3) Plan to implement this lifestyle behavior sometime in the next few months;

(2) Recently (within the previous 6 months) began this lifestyle behavior;

(1) Have been maintaining this lifestyle behavior for $6+$ months.

Next, the patient is asked to rate their level of confidence to incorporate the same list of behaviors into their lifestyle using the following scale:22 
(3) Very confident;

(2) Somewhat confident;

(1) Not very confident.

Following completion of the surveys, the health care provider can assess the responses. Behaviors that are listed in the maintenance stage with high confidence of continuing should be positively reinforced. If the patient is maintaining a behavior, but only somewhat confident or not very confident about sustaining the behavior, a conversation should occur regarding the patient's lack of confidence and strategies should be developed to overcome any barriers identified through the conversation. Research indicates an individual will have the greatest success incorporating a behavior that they are both ready and confident to change. ${ }^{15,19}$ Using this knowledge, the provider can encourage the early adoption of a behavior the patient is ready and confident to implement. Research also suggests that, with success, the patient may be more confident to make a change they felt less sure about at baseline. ${ }^{24}$ Use of the Readiness and Confidence to Change surveys helps the health care professional to determine which lifestyle behaviors to target first for optimal success. Behaviors that the patient is not interested in or not confident in adopting should also be discussed. This conversation should include the benefits that may be gained from initiation of the behavior as well as the risks associated with maintenance of the current behavior. The questionnaires can be administered at baseline to direct lifestyle medicine programming and at follow-up to detect progress and changes in readiness or confidence of behavior change.

\section{Development of a personalized lifestyle medicine program}

After identifying problem areas and discussing possible lifestyle medicine treatment solutions, a formal plan of action should be developed. The health care professional should direct this process, but do so interactively, considering feedback from the patient.

It is well accepted that conscious goals affect action, but there is little consensus on the best method of goal setting in clinical practice. ${ }^{24} \mathrm{~A}$ review by Bodenheimer and Handley found that, in the health care setting, goal-setting research favors specific proximal goals formulated collaboratively with the patient rather than vague long-term goals set by the clinician alone. ${ }^{24}$ The SMART (Specific, Measurable, Attainable, Relevant, Time) goal setting technique is one method that includes each of these characteristics.

When setting a goal it is best to be specific about the objective. Rather than set a goal to improve blood pressure, which is unclear and ambiguous, a more specific goal may be to consume eight or more fruit and vegetable servings each day to reduce blood pressure. This goal is specific and measurable, ie, the second characteristic of a SMART goal. The patient can keep a food log and track the number of fruit and vegetable servings consumed daily. A measurable goal allows the patient to see whether or not they are making progress toward or meeting their goal, as well as assist them in keeping on track. The third characteristic of a SMART goal is ensuring the goal is attainable. This component incorporates the idea of self-efficacy. If the patient is currently consuming only one serving of produce daily, it may not be realistic to set a goal to increase this amount to eight or more servings daily. Instead it may be more realistic to set the goal for something more attainable, like three or more servings daily to start. This smaller change may increase the patient's level of confidence in achieving the goal and, thus, improve the chance of success. The goal must also be relevant. Recognizing that the patient wants to decrease their blood pressure and educating them that a nutrition plan with increased fruit and vegetables has been shown to do so, increases the relevancy of this goal to the patient and increases the motivation to modify the behavior. The last component of a SMART goal is setting a time-specific goal. As stated previously, setting a proximal goal seems to be more effective than setting a distal goal. This target date or deadline helps the patient focus on completing the goal with a sense of urgency and does not allow the patient to put off completion for a later date. Using the SMART technique, an appropriate goal for this patient to lower blood pressure would be, "By the end the month, I will consistently consume three or more fruit and vegetable servings daily as recorded in my nutrition diary. By the sixth month, I will have increased my produce intake to six servings daily and by the end of the year I will be consuming eight or more fruit and vegetable servings each day."

\section{Self-care monitoring tools}

Self-care monitoring is an important piece of the behavior change process. Self-monitoring not only increases personal awareness of behavior and its effect on health indicators, but also enlists joint participation in behavior modification on the part of the patient. Literature exists suggesting that selfmonitoring in itself is therapeutic and, through the process of self-monitoring, desired behavior increases and undesired behavior decreases. ${ }^{25,26}$ The type of self-monitoring tool depends on the patient's unique history and goals, but may include a food diary, lifestyle journal, pedometer, home blood pressure monitor, and/or glucometer. 
Table 3 Lifestyle behavior and health indicator data examples for use in a lifestyle journal

\begin{tabular}{|c|c|}
\hline & Unit of measurement \\
\hline \multicolumn{2}{|c|}{ Lifestyle behaviors } \\
\hline \multirow[t]{3}{*}{ Physical activity } & Minutes \\
\hline & Distance \\
\hline & Pedometer steps \\
\hline \multirow[t]{3}{*}{ Nutrition } & Calories \\
\hline & Fruit and vegetable servings \\
\hline & Carbohydrate servings \\
\hline Sleep & Hours \\
\hline Tobacco use & Number of cigarettes smoked \\
\hline Alcohol & Servings consumed \\
\hline Stress & $\begin{array}{l}\text { I-5 scale, I feeling stress free, } 5 \text { feeling } \\
\text { overwhelmed, frantic and out of control }\end{array}$ \\
\hline \multicolumn{2}{|c|}{ Health indicators } \\
\hline Blood pressure & $\mathrm{mmHg}$ \\
\hline Blood sugar & $\mathrm{mg} / \mathrm{dL}$ \\
\hline Weight & $\mathrm{lb}$ \\
\hline
\end{tabular}

The habit of recording food consumption has been correlated with successful weight loss. ${ }^{26}$ Food diaries vary in complexity and may include calorie count and nutritional breakdown or simply track the number of fruit and vegetable servings consumed daily. Food diaries can be used in combination with glucometer readings or home blood pressure logs to help patients appreciate how nutrition can improve or worsen blood sugar and blood pressure.

Lifestyle journals track a variety of behaviors and can be tailored to fit individual goals. Categories to be monitored in a lifestyle journal may relate to nutrition, physical activity, sleep, stress, alcohol consumption, and tobacco use. As stated previously, tracking food consumption can lead to weight loss. The same study found that tracking physical activity increases the amount of exercise completed and can also lead to successful weight loss. ${ }^{27}$ Increases in physical activity and decreases in body mass index were also observed in people who wear pedometers, another effective self-monitoring tool. $^{28}$

Although they are not lifestyle behaviors, weight, blood pressure, and blood sugar can also be logged in a lifestyle journal. Tracking glucose, blood pressure, and weight in combination with lifestyle behaviors can help identify patterns between lifestyle and health indicators as well as reinforce targeted behaviors when positive changes are observed. In addition to identifying lifestyle-related patterns in biometric data, regular use of glucometers and home blood pressure monitors has been shown to increase disease control and may decrease disease-related morbidity and mortality. ${ }^{29-31}$

Table 3 lists examples of lifestyle behaviors and health indicators that could be tracked using a personalized lifestyle journal. When creating a personalized lifestyle journal, monitoring parameters should be selected to correspond with the individualized SMART goals described above. Each SMART goal is measurable, and the log should represent the method for measuring progress towards goal achievement.

\section{Conclusion}

Modifiable lifestyle behaviors, including tobacco use, poor nutrition, and lack of physical activity, continue to top the list of actual causes of death in the United States. Changing these behaviors could prevent a majority of premature chronic disease cases. Behavior change, however, is a complex process and can be frustrating to both the patient and the health care professional. Several tools exist to assist in this process. Many of the tools described above practically apply one of three common health behavior change theories (the transtheoretical model of behavior change, the health belief model, and social cognitive theory). Use of these tools in clinical practice may increase the rate of success in modifying lifestyle behaviors, and in effect, reduce cardiovascular risk.

\section{Disclosure}

The authors report no conflicts of interest in this work.

\section{References}

1. Mokdad AH, Marks JS, Stroup DF, Gerberding JL. Actual causes of death in the United States, 2000. JAMA. 2004;291:1238-1245.

2. World Health Organization. Chronic diseases and health promotion. Preventing chronic diseases: a vital investment. Geneva, Switzerland: World Health Organization; 2005. Available from: http://www.who.int/chp/ chronic_disease_report/part1/en/index11.html. Accessed July 7, 2013.

3. Chobanian AV, Bakris GL, Black HR, et al; National Heart, Lung, and Blood Institute Joint National Committee on Prevention, Detection, Evaluation, and Treatment of High Blood Pressure; National High Blood Pressure Education Program Coordinating Committee. The Seventh Report of the Joint National Committee on prevention, detection, evaluation, and treatment of high blood pressure: the JNC 7 report. JAMA. 2003;289:2560-2572.

4. National Cholesterol Education Program Expert Panel on Detection, Evaluation, and Treatment of High Blood Cholesterol in Adults (Adult Treatment Panel III). Third report of the National Cholesterol Education Program (NCEP) expert panel on detection, evaluation, and treatment of high blood cholesterol in adults (Adult Treatment Panel III) final report. Circulation. 2002;105:3143-3421.

5. Garber AJ, Abrahamson MJ, Barzilay JI, et al. AACE comprehensive diabetes management algorithm 2013. Endocr Pract. 2013;19:327-336.

6. Rainforth MV, Schneider RH, Nidich SI, Gaylord-King C, Salerno JW, Anderson JW. Stress reduction programs in patients with elevated blood pressure: a systematic review and meta-analysis. Curr Hypertens Rep. 2007;9:520-528.

7. Minami J, Ishimitsu T, Matsuka H. Effects of smoking cessation on blood pressure and heart rate variability in habitual smokers. Hypertension. 1999;33:586-590.

8. Boule NG, Haddad E, Kenny GP, Wells GA, Sigal RJ. Effects of exercise on glycemic control and body mass in type 2 diabetes mellitus: a metaanalysis of controlled clinical trials. JAMA. 2001;286:1218-1227. 
9. Haimoto H, Sasakabe T, Wakai K, Umegaki H. Effects of low-carbohydrate diet on glycemic control in outpatients with severe type 2 diabetes. Nutr Metab (Lond). 2009;6:21.

10. The Look AHEAD Research Group; Pi-Sunyer X, Blackburn G, Brancati FL, et al. Reduction in weight and cardiovascular disease risk factors in individuals with type 2 diabetes. Diabetes Care. 2007;30: 1374-1383.

11. Prevention Publishing Inc. Lifestyle is Medicine, 2011. Available from: http://lm-rx.com/. Accessed June 3, 2013.

12. McGinnis MJ, Foege WH. Actual causes of death in the United States. JAMA. 1993;270:2207-2212.

13. Prochaska JO, DiClemente CC. Stages and processes of self-change of smoking: toward an integrative model of change. J Consult Clin Psychol. 1983;51:390-395.

14. Fiore M. Tobacco use and dependence guideline panel. Treating tobacco use and dependence: 2008 update. Rockville, MD: US Department of Health and Human Services, Public Health Service; 2008. Available from: http://www.ncbi.nlm.nih.gov/books/NBK63952/. Accessed July 7, 2013.

15. Zimmerman GL, Olsen CG, Bosworth MF. A 'stages of change' approach to helping patients change behavior. Am Fam Physician. 2000;61:1409-1416.

16. Rosenstock IM, Strecher VJ, Becker MH. Social learning theory and the health belief model. Health Educ Behav. 1988;15:175-183.

17. Burke BL, Arkowitz H, Menchola M. The efficacy of motivational interviewing: a meta-analysis of controlled clinical trials. J Consult Clin Psychol. 2003;71:843-861.

18. Miller WR, Rollnick S. Motivational Interviewing: Preparing People for Change. New York, NY: Guilford Press; 2002.

19. D’Agostino RB Sr, Vasan RS, Pencina MJ, et al. General cardiovascular risk profile for use in primary care: the Framingham Heart Study. Circulation. 2008;117:743-553.

20. Goldman RE, Parker DR, Eaton CB, et al. Patients' perceptions of cholesterol, cardiovascular disease risk, and risk communication strategies. Ann Fam Med. 2006;4:205-212.

21. Lenz TL, Gillespie ND, Faulkner MA, et al. Lifestyle-medicine related cardiovascular risk factor changes in employees participating in a pharmacist-run risk reduction program. Available from: www. pharmacy.umn.edu/innovations/vol3no4/home.html. Accessed May 21, 2013.
22. Gillespie ND, Lenz TL. Implementation of a tool to modify behavior in a chronic disease management program. Advances in preventive medicine. Available from: http://www.hindawi.com/journals/apm/2011/215842/. Accessed July 7, 2013.

23. Locke EA, Latham GP. Building a practically useful theory of goalsetting and task motivation. A 35-year odyssey. Am Psychol. 2002;57: $705-717$.

24. Bodenheimer T, Handley MA. Goal-setting for behavior change in primary care: an exploration and status report. Patient Educ Couns. 2009;76:174-180.

25. Bellack AS, Rozensky R, Schwartz J. A comparison of two forms of self-monitoring in a behavioral weight reduction program. Behav Ther. 1974;5:523-530.

26. McFall RM, Hammen CL. Motivation, structure, and self-monitoring: role of nonspecific factors in smoking reduction. J Consult Clin Psychol. 1971;37:80-86.

27. Carels RA, Darby LA, Rydin S, et al. The relationship between self-monitoring, outcome expectancies, difficulties with eating and exercise, and physical activity and weight loss treatment outcomes. Ann Behav Med. 2005;30:182-190.

28. Bravata DM, Smith-Spangler C, Sundram V, et al. Using pedometers to increase physical activity and health: a systematic review. JAMA. 2007;2:227-229.

29. Martin S, Schneider B, Heinemann L, et al. Self-monitoring of blood glucose in type 2 diabetes and long-term outcome: an epidemiological cohort study. Diabetologia. 2006;49:271-278.

30. Karter AJ, Ackerson LM, Darbinian JA, et al. Self-monitoring of blood glucose levels and glycemic control: the Northern California Kaiser Permanente Diabetes Registry. Am J Med. 2001;111:1-9.

31. Pickering TG, Houston-Miller N, Ogedegbe G, et al. Call to action on use and reimbursement for home blood pressure monitoring: a joint scientific statement from the American Heart Association, American Society of Hypertension, and Preventive Cardiovascular Nurses Association. Hypertension. 2008;52:10-29.

\section{Publish your work in this journal}

Psychology Research and Behavior Management is an international, peerreviewed, open access journal focusing on the science of psychology and its application in behavior management to develop improved outcomes in the clinical, educational, sports and business arenas. Specific topics covered include: Neuroscience, memory \& decision making; Behavior

\section{Dovepress}

modification \& management; Clinical applications; Business \& sports performance management; Social and developmental studies; Animal studies. The manuscript management system is completely online and includes a quick and fair peer-review system. Visit http://www.dovepress. com/testimonials.php to read real quotes from published authors. 